\title{
The Overqualified Artist: The Regulation of Mimesis in Plato's Republic
}

\author{
Brian Treanor \\ Boston College
}

\section{Introduction}

The first-time reader of Plato's Republic is often shocked at the rough treatment and eventual exclusion of art in Plato's ideal state. The Republic has been described as one of the greatest attacks on democracy and freedom in the history of Western thought, and the restrictive treatment of art in Book III can seem unduly harsh to the modern reader. By the time that the interlocutors reach Book X it seems that all non-craft art has been entirely banished from the polis due to its corrupting impurity. To the modern reader, the extreme nature of this proclamation is highlighted by our historical knowledge. Even the more brutal and repressive totalitarian states of the last century - for example, those of Hitler's Third Reich and the Soviet Union under Josef Stalin-did not go so far as to completely outlaw art.' There is a second surprise for the first-time reader of the Republic in Book X insofar as this final book seems to contradict, disregard, or forget the conclusion that the interlocutors reached concerning art in Book III. This apparent contradiction calls for a close reading and interpretation of the text in light of both Plato's conception of mimesis and the overall project of the Republic.

The problem lies in the apparent incommensurability of the discussions on the suitability of art, specifically poetry, for the polis as put forth in Book X and Book III. Book III seems to allow that some forms of poetry and imitation will be acceptable in the state while others will be rejected. The discussion of poetry in this section concludes that "we ourselves, for our souls' good, should continue to employ the more austere and less delightful poet and taleteller, who would imitate the diction of the good man and would tell his tale in the patterns we prescribed in the beginning ... litalics minel" (398b). ${ }^{2}$ However, in Book X it appears that all imita- 
tive poetry has been excluded from the state, allowing for no distinction similar to the one with which Book III concludes. The opening lines of Book X expose this apparent leap in logic in the classification of poetry by "refusing to admit at all so much of it as is imitative, for that is certainly not to be received" (595a). Book III seems to recognize that imitative poetry is very powerful and can be either harmful or beneficial, and must therefore be regulated. Book $\mathrm{X}$ appears to take these concerns much further by excluding all imitative poetry, for various reasons, without regard to any of the possible benefits that might be gained from it. How can we reconcile these two treatments of mimeses? Has Plato forgotten or contradicted his position in Book III in Book X? Obviously, he has not. The theory of art in the Republic may be complex and may be distasteful, but it remains consistent. Although we will be able to reconcile the treatments of art and mimeses in Books III and $\mathrm{X}$, we will find that such reconciliation raises new problems for the polis. Chief among these new difficulties is finding a citizen of Plato's city-state who is both able and willing to pursue imitative art in the restricted manner in which it is to be allowed in the Republic.

\section{Book III}

Art is first discussed in relation to the education of the guardian class. The education of the guardians will begin with gymnastics and music. Music, under which Plato includes tales and poetry, is one of the first types of education to which the young guardiansto-be are exposed. Plato distinguishes two types of tales that will be used in the process of education, one true and the other false. Education eventually uses both true and false tales, but it begins with false tales told to children. "We must begin, then, it seems, by a censorship over our storymakers, and what they do well we must pass and what not, reject. And the stories on the accepted list we will induce nurses and mothers to tell the children and so shape their souls ..." (377c). However, most commonly told stories must be rejected either for their subject matter or the manner in which the tale is told. It should be noted that Plato is not at all adverse to lying to the citizens in the course of education-nor in 
the course of governing the city-however, there are some lies that he will not sanction. Given Plato's resolve to reach the truth, the reader should be suspicious-if not downright indignant-that he sets forth a policy of educational lies so cavalierly. Indeed, this is not the only passage in which Plato places an important governmental function on a foundation of lies told to the citizens. ${ }^{3}$ Thus, in Book III, it is obvious that Plato's aversion is not to lying itself, but to the content of the lie and how the content may effect the young guardians.

In Book III, Plato undertakes a lengthy inquiry into mimesis in order to determine how art of this type (imitative) will affect the education of the guardians, and thus the polis. He inquires into the nature and results of art because he is well aware of the manner in which art influences the noble and common people alike, shaping their views. Plato enters this broad discussion of art by examining poetry. Poetry, including the forms of poetry that we might refer to as theater, was the major form of artistic expression for the Greeks, used for both entertainment and education.

According to Plato, poetry exists in three main forms. Poetry can either "proceed by pure narration or by narrative that is effected through imitation, or by both" (392de). A modern example of pure narration exists in the capable news journalist. A good journalist simply reports the information in a clear and easily understandable manner; a manner that remains disinterested in the sense of remaining impartial concerning the facts being reported. The reporter should not embellish the story by changing his voice, body language, or delivery to imitate the people about whom he is reporting. Purely imitative poetry exists in a modern format in every form of acting. In movies, television and on stage the highest goal is imitation so perfect and seamless that "it seems real." Actors are praised and paid for their ability to "become" a variety of characters. Finally, an example of what Plato might call a mixed format exists in a National Geographic documentary, wherein some of the footage is taken straight from things as they happen, while other scenes are recreated in a manner similar to a fictional movie. In such a format, much of the footage is shot in a narrative or documentary style, but scenes that would be difficult or dangerous to reproduce as they actually occur are staged and filmed to give the illusion that they were filmed as the events took place. 
Given his threefold distinction in poetry, Plato undertakes to determine which forms will be acceptable in the perfect polis. Before he can pass judgment on the different forms of poetry, he must determine what is essential to each; and this entails divining the nature of mimesis. Furthermore, it will be imperative to ask: "Do we wish our guardians to be good mimics or not?" (394e). Finally, do we wish to allow imitative poets to ply their trade in the polis for any of the citizens? That is, do we wish any of the citizens of the Republic to view imitation? Pure narration is explained simply enough at 393d-394b with an example of a Homeric passage delivered as a report, in a monotone devoid of changing cadence or imitation of characters. Plato takes this form of poetry to be a simple and accurate reporting of the facts. Imitation, despite being present in its pure state in the Greek theatrical forms of tragedy and comedy, takes more explanation in order to ascertain its nature.

One of the factors that will weigh heavily on the fate of imitation in the city-state is Plato's insistence on a society ordered by the maxim "one man, one vocation." Plato believes that insistence on this model of one and only one job is a form of justice. "The proper functioning of the money-makers, the helpers, and the guardians, each doing his own work in the state ... would be justice and would render the city just" (434d). As we will see, this universal rule will cause problems even for the forms of art that are to be allowed in the polis. For each person to realize his potential, Plato believes that he should exert himself in the vocation to which he is best suited. To achieve as much as possible, one should not divide one's resources. Even if one's best talent was imitation it seems to follow that no one would be able to imitate several things as well as one, given that people are unable to do several things as well as they can do one. Therefore, the purely imitative poet and the epic poet are already censured on the basis that, even if imitation is to be allowed in the city, each imitator will only be allowed to imitate that which he imitates best. Furthermore, the imitation of even one thing is also found to be harmful. Should a person choose to actually pursue his work in society - given that a person is to focus his efforts on one thing in life-or to imitate things in art, which contributes nothing tangible to the commu- 
nity? This question verges on the rhetorical for Plato. Because each person is to have one vocation or duty within the society, there is no room for imitators, who contribute nothing as mere imitators, and who waste the energy properly reserved for one's work if imitation is a second vocation.

Viewed as an educational tool however, imitation can be seen as good in some cases and bad in others. Indeed, for a variety of reasons, Plato is concerned with imitation primarily, if not solely, with regard to its value as a tool for education. Imitation is good insofar as it trains a person to develop the personality and characteristics suited to his station in life. It does this by providing an example for emulation, a model on which to base one's own behavior. For example, if the guardians are to imitate, "they should from childhood up imitate what is appropriate to them-men, that is, who are brave, sober, pious, free, and all things of that kind" (395c). Imitation in such cases would be imitation of the fully developed persons that the young guardians are to become.

Imitation can, obviously, be just as detrimental to growth and development. Insofar as a person imitates another person, he attempts to mimic that person in speech, action, and demeanor. Such mimicry is likely to develop the imitated characteristics simply by repetition and habituation. The potential for imitation to subtly effect and eventually alter the character of the imitator-and the character of the frequent observer of imitation-is at the very heart of Plato's objection to mimesis. The power of mimetic art is thus worthy of both respect and fear. If imitation is of the proper sort, it can be used to provide a proper model that the citizens can look to in order to imitate. Indeed, if Plato's ideas about the power of art to influence the viewer are correct, the good example given by good imitative art will positively effect the viewers even without their conscious emulation of the themes in the art. If, however, the mimetic art provides an improper model, the result will be the exact opposite of the positive mimetic example. It is easy to imagine that a normally well-spoken person might, after playing a foulmouthed cab driver for months in a play, find himself cursing in everyday speech. This type of imitation-of any people who are not themselves guardians of the highest ability and wisdom-could easily be disastrous for the developing mind of a young would-be guardian. 
Given this discussion of imitation and the potential benefits and possible evils associated with it, Plato must determine to what extent, if any, imitative arts will be allowed to flourish in the polis. Plato identifies and defines two types of imitation and three types of poetry in Book III of the Republic. Imitation itself is either good, if it provides a good example for the viewer, or bad, if its example is neutral or detrimental to the viewer. The three types of poetry are distinguished by the extent they utilize imitation: 1) narration, which will involve as little imitation as possible; 2) pure imitative poetry as seen in tragedy; and, 3 ) a mix of these two, as seen in epic poetry. It is important to keep in mind that even narrative-style poetry will contain some imitation. "The narrative that [the good man] will employ will be of the kind that we just now illustrated by the verses of Homer, and his diction will be one that partakes of both, of imitation and simple narration, but there will be a small portion of imitation in a long discourse" (396e). Because imitation is inherently dangerous - insofar as it submerges one's own personality for the personality imitated-imitation should be used as little as possible. Therefore the style of "pure" narration should be the style of the perfect state. Although this narrative style imitates, it does so as little as possible. It goes without saying that the small amount of imitation that will exist in the poetry that is allowed will be imitation of good men who embody the Platonic ideal. "A man of the right sort, I think, when he comes in the course of his narrative to some word or act of a good man will be willing to impersonate the other in reporting it, and will feel no shame in that kind of mimicry" (396d). The poet will "by preference [imitate] the good man when he acts steadfastly and sensibly, and less and more reluctantly when he is upset by sickness or love or drunkenness or any other mishap" (396d). By the end of the treatment in Book III, Plato seems to be satisfied with the limits and restrictions imposed on poetry and its use in the educational process. The interlocutors have greatly restricted art, censuring all of it that does not provide examples of thoughts, actions, or emotions that would be proper for people who are governed by their rational part, people who have perceived the Good. 


\section{The Seeming Contradiction}

Given these conclusions, it comes as a surprise that, in the opening lines of Book X, Plato refers to the earlier treatment of imitation and poetry "in refusing to admit at all so much of it as is imitative" (595ab). What can Plato possibly mean by stating that the conclusion of the earlier discussion was that all poetry that imitates would be banished from the polis? It seemed clear that the discussion of art and imitation in Book III ends, not with the exiling of all art, but with the strict censuring of art to insure that the art in the polis will be art that contributes to the justice and harmony of the state, rather than art that detracts from it. The distinctions between the three types of poetry Plato recognizes can be helpful here. We see right away that the purely imitative style and the so-called mixed style of poetry are dangerous in Plato's view. The purely imitative type of poetry "will attempt, seriously and in the presence of many, to imitate all things, including ... claps of thunder, and the noise of wind and hail and axles and pulleys, the notes of trumpets ... and the cries of dogs, sheep, and birds" (397b). The mixed imitative type of poetry is unacceptable for the same imitative excesses and on the principle that "there is no twofold or manifold man among us, since every man does one thing" (397e). Indeed, these two styles of poetry were effectively banned in Book III.

However, Book III allows the narrative style of poetry - which is sometimes referred to confusingly as if it were "non-imitative poetry"- to exist in the polis: and this kind of poetry does imitate to some extent. Narrative style poetry imitates to the extent that the good man would deign to imitate. ${ }^{+}$At the beginning of Book $\mathrm{X}$, Plato is referring to the exclusion of all imitative style poetry (i.e. the poetry of pure imitation and the mixed-style poetry) not to the exclusion of imitation itself.' Narrative-style poetry, which uses imitation as little as possible and only so far as it is good, is still allowed in the state. Given this clarification of the difference between banning imitative-style poetry and banning imitation itself, Book $X$ should be read as an addition to, or expansion of, the discussion in Book III. In Book X Plato re-opens the discussion of imitation in order to determine the extent that imitation itself can 
be allowed in poetry of the narrative style-and, by extension, in all the other arts of the polis-and to introduce his final philosophical discussion concerning justice and injustice in the man and in the state.

\section{Book X}

For Plato, imitation is inherently degenerate because it is so far removed from the truth. What is imitation? It is a copy, an image, of something. Furthermore, it is strictly speaking not even the copy of some-thing, but a copy of an appearance (one of many appearances) of something. The object that art imitates is itself merely an image of reality. Using, as Plato does, the example of painting, we can first see that a painting of a couch is not a couch. We can not relax on the couch of the painting. The painting of the couch is a copy of the couch, but it is less a couch, it has less "couchness" then an actual couch. However, the painting of the couch is even less than an image of a couch, because it is really only an image of the couch from one perspective. It is an image of only one appearance of the couch. Like Plato's example of the "creator" who "creates" any and all things by carrying around a mirror and capturing images of things he encounters, the painting captures only one appearance of one couch. There are both many other possible appearances of the couch in the mirror, or the painting, and many other actual couches which are not captured or represented in the mirror or painting. Given this understanding, we can see how little the imitation of the couch in painting helps in the understanding of the particular couch, let alone couch-in-itself, or the eidos of couchness. Imitation captures "the appearance of [things], but not the reality and the truth" (596e).

However, the inadequacy of imitation goes even deeper in light of (or, perhaps, in distance from the light of) Plato's celebrated Theory of Forms." The particular couch, which is the object of imitation in either the mirror or the painting, is itself merely an image or reflection of the Form of couch. Plato theorizes that every perceptible object is merely an image of a Form. The particular is both less real and, more importantly for the discussion of imitation, less true than the universal. Given Plato's metaphysical 
framework, an imitation of a particular couch in a painting is very far from the truth indeed. The painting of a couch is an image of an appearance of the Form. The imitation is at least three times removed from the truth.

If all imitation is at least three steps back from the truth, what is to distinguish good or acceptable imitation from bad imitation? The answer lies in the relation of the "third step" away from the truth. The mirror is an excellent example of bad imitation. The mirror makes its copy of the couch by copying an appearance of the couch, not by copying the couch itself. It copies the appearance of the image (the couch) of the truth (the form of couch). In other words, the painter imitates with his eye on the physical manifestation of the couch in front of him, not with an 'eye' to the form of which the physical couch itself is merely a reflection. The bad imitation has this specific relation to that which it imitates: it imitates the appearance of its object; that is, it imitates without an understanding of the form of the thing that it imitates. It is now clear that the type of imitation outlawed in Book III is the imitation that has no knowledge of reality (the forms). The commonthat is "bad"-imitator has "no knowledge he does not see, and therefore cannot represent, the ideal forms."

In contrast, imitation which would be less objectionable would be a painter who, while painting the couch, has not the particular couch in front of him in mind, but the eidos of couch of which this particular couch is an example. Such an artist might not even have a physical couch present while painting, creating his image from the form itself. Just like the expert craftsman who makes a good couch, he creates with the form in mind, rather than a mere appearance. In his article "Imitation in Plato's Republic," Tate claims that Plato "leaves it to be understood that the poet who is imitative in the sense in which the guardians are permitted to be imitative will produce a direct copy of reality [italics mine]." This interpretation would put some forms of artistic imitation one the same level as expert craftsmanship or practice. Both the expert craftsman and the good artistic imitator would create their product while apprehending the form of that which they are creating or imitating. Indeed, under this interpretation, good imitation is actual creation in the same sense as expert craftsmanship, for both are 
imitating the form. This "mimesis of the form"-as opposed to ordinary mimesis of the image of the form-that Tate wants to ascribe to good imitation would eliminate virtually all the controversy surrounding the apparent banning of imitation in Book X of the Republic. However, it is unclear that Plato would agree that the kind of imitation embodied in poetry would be capable of creating something as real as the act that the art is depicting. For example, are we ready to claim that a poetic description of courage that incorporates this "good mimesis" is as courageous as an act of courage? Due to his philosophical foundation, it is not likely that Plato would have agreed completely with this characterization of good imitation, if only because of his insistence on a person being expert at only one skill."

However, even if we are to disagree with Tate concerning the artist's ability to successfully produce a direct copy of reality (the form) in his art, there remains a valid distinction between good and bad imitation. While good imitation is three steps back from the truth, it has the truth in mind to some extent. Bad imitation is three steps back and one to the side, so to speak, in the sense that one of the steps back copies an appearance of the previous step rather than the previous step itself. Good imitation in a painting of a couch will at least attempt to manifest the form of the couch, to copy the essential features of the couch. Bad imitation will be content to copy the physically perceived image of the couch. Therefore, to be a good imitator, one must apprehend the form of the thing that is being imitated, rather than imitate from the physically observable characteristics of the thing one is imitating.

Thus, there are two distinct prescriptions with which the lawgivers of the Republic must concern themselves. Plato's state will have to regulate the amount of imitation in poetry by allowing only narrative style of poetry and, further, regulate the type of imitation in the permitted style of poetry to insure that it is good imitation. Therefore the narrative style of poetry, which may contain some imitation, will contain only imitation which has in mind the forms rather than the particulars while it is imitating. 


\section{New Difficulties}

Although this interpretation clears up some common difficulties resulting from a less than clear and consistent use of the term "imitation" in Plato's treatment of art and poetry, it also fails to hurdle some significant obstacles and raises some interesting new questions. The first thing that we will have to assess, now that we have adopted this reading of Plato's position, is what the acceptable Platonic artist will look like. Given the extensive restrictions placed on the practice of art in the polis, who will be both able and willing to undertake artistic endeavors? Secondarily, given these same restrictions, what will the art of Plato's polis look like? Interestingly, the answers to both of these questions present parallels to modern aesthetic theory, in particular to the art and artists depicted in the later stages of the Hegelian-like development of art described by Arthur Danto in his essay "The End of Art."'0

At the very outset of such a comparison, we must note that we will not be able to represent either author in his totality if a comparison is to be fruitful. Although Danto's position in history enables him to take account of Plato's thought, Plato does not share this ability with regard to Danto. Given a certain incommensurability between the two authors, we will have to bracket some of Danto's project in order to fruitfully compare the art and artists of Danto's second and third models with the art form that Plato ultimately allows in the Republic. For example, we will be forced to bracket some of the strong Hegelian teleology of Danto's model.

At first glance, it may seem that Plato and Danto have little more in common than their concern with a utopia of sorts, one Hellenic and the other Hegelian. Nevertheless, in spite the enormous differences between Plato and Danto in terms of the type of philosophizing they are doing, they goal they have in mind for their projects, etc., there are similarities that warrant examination. In particular, they are both deeply concerned with the relationship between philosophy and art. The similarity of these concerns is evident in the following passage from Danto's essay "The End of Art," in which he acknowledges his debt to the thought of Hegel. 
'It is no doubt the case,' Hegel writes in his Philosophy of Fine Arts, 'that art can be utilized as a mere pastime and entertainment ...' Art is truly free, he goes on to say, only when 'it has established itself in a sphere it shares with religion and philosophy, becoming thereby one mode more and from through which ... the spiritual truths of the widest range are brought home to consciousness.' "I

This passage from Danto reads as an explicit Platonic treatise on good imitation might read-if we set aside the radical difference between what "spiritual truth" might have meant for Plato as opposed to Danto or Hegel. Before proceeding, we will first get a picture of just who will be capable of practicing art in Plato's polis and, once we have done so, we will then be able to compare this Platonic artist with some of Danto's characterizations of artists.

Plato means to allow one type of poetry into the state-the socalled narrative style. Further, Plato insists that, insofar as it is imitative, the imitation of the narrative style will be restricted to the acceptable form of good imitation, imitation with the form or truth of the thing imitated in mind. Plato uses poetry as an archetypal example and intends to restrict other forms of art in a similar manner. However, given the structure of Plato's state, how will such art be undertaken? The unity of the polis and Plato's understanding of justice are built on the principle of one man, one work. Therefore if a person is an artist, art must be his sole vocation. However, the only art permitted in the state is art that imitates with the form foremost in mind. If a person can fix his eye on the form of a thing, why would he choose to labor at a third generation imitation (art), when he is able to construct a second generation image of truth by constructing the very thing he might have imitated? Even if we accept the possibility of a good imitation allowed in the polis, who would choose to produce impractical imitations of the forms (good mimetic art) rather than practical images of the forms (crafts)? "If [a person] had genuine knowledge of the things he imitates he would far rather devote himself to real things than to the imitation of them" $(599 \mathrm{~b})$. Who would suf- 
fer to be a mere imitator in the state, rather than an actual craftsman? It cannot be one who masters the art of imitation, for his eye would not be on the form of that which he imitates, and his brand of art would be excluded from the state. This it seems that there is an artistic style and content which will be admitted in the state, yet remain unpracticed because any person worthy enough to practice the art is, by definition, overqualified to do so.

There is an excellent solution ready at hand for this problem if we search the population of Plato's state. In order for the state to take advantage of the power of art to educate (or indoctrinate) the citizens, we need to find a type of person who is able to apprehend the form to be imitated and who will also condescend to merely imitate truth via art rather than create actual instances or embodiments of the form. Where can we find a person with the mental ability to apprehend the forms, without the desire or ability to labor and create the actual things they would imitate? Fortunately for Plato, his polis will have a ready-made supply of people who fit this description. The people who will educate through poetryand other forms of art-via imitation will be the members of the ruling population who have the mental capacities to imitate properly, but are hampered by physical limitations: the old and the injured members of the guardian class.

While this suggestion seems quite ridiculous at first, it makes good sense for the city. What is the state to do with the guardian who is maimed in defense of the civilization or the ancient statesman who is replaced by younger guardians who are stronger of body and keener of mind? If we allow the infirm to educate through acceptable forms of artistic imitation, they will not become a mere burden on society. Indeed, Plato himself calls the man who no longer contributes to society while living on in the polis as a dependent an example of "the greatest of all [of the] evils" resulting from the breakdown of justice (552). Without the outlet of working as educators, the only logical choice for the elderly or injured would be an extension of the eugenic practice of the polis to include "involuntary euthanasia" of the elderly or injured. If allowed to work as educators such people will be able to give the other citizens the benefits of their keen perception of the form, or forms, which they apprehend. Only among the ranks of the physi- 
cally infirm citizens will we find people who are both able and willing to pursue artistic imitation under the restrictions imposed by the state. Thus is because a keen mind often outlasts the body in which it resides. ${ }^{12}$ The bodies of the guardians will deteriorate while their minds are still capable of contributing to the state.

There is precedence for this policy of education by the elders. We can see this in the relegation of certain guardians and assistants to watch over the child-guardians when they go to war as observers. Certainly, the vocation of these men and women calls them to the battle. They are more suited for active participation in the battle than for the role of observer. Nevertheless, these people are ordered to, and consent to, a rearguard role for the betterment of the next generation of guardians. We must read this in one of two ways, either of which will make our point and allow some guardians to practice poetry in the city for the education of the citizens. Either the rearguard soldiers at the "instructional war" are older soldiers who can no longer excel in the physical rigors of combat, but have knowledge of the martial forms and may thus instruct the guardians-to-be as to what is happening on the battlefield before them. Or, the rearguard is made up of soldiers who are able-bodied enough to fight at the front, but who are ordered to protect the children because it is in the best interests of the city as a whole to train the next generation of guardians. Because the city is concerned with the happiness of the whole rather than the happiness of the individual, the soldiers so ordered would consent to not practice their practical skill (the craft of war) in favor of accepting a lesser job (interpretation and story telling for the education of the children) for the good of the city. Like the philosopher who descends back into the cave to rule, they accept this burden as the price of their role in the perfect polis.

Admittedly this analysis does not solve all the obscurities and inconsistencies that arise regarding artistic endeavors within Plato's state. Would the rulers allow the position of educator, an honored and critically important role within the state, to be filled by the infirm? Because the limitations in question are the results of service to the state, there is good reason to believe that the people who have been injured at war or grown old as rulers would still have the respect and admiration of the citizens. Outside the ranks 
of the citizens who have been stricken with injuries or age, the only solution to the question of who could practice art is analogous to the solution for creating the rulers themselves: either the artists must become philosophers, or the philosophers must become artists.

Given the unique constitution and training required to become a guardian, it is not practical to insist that the artists become philosophers. However, if we allow education to take place through good mimetic art practiced by older or infirm people who are able to apprehend the forms, we are, in fact, choosing the second option and allowing some philosophers to become artists. The current generation of guardian-rulers cannot split their resources between two vocations (ruling and education). Therefore, it is only among the ranks of the "retired" philosophers that we will find people who can educate through art. The only qualifying statement is that these philosophers, like the musical, poetic Socrates of the Phaedo, will pursue art only at the very end of their lives; and they will do so as a final service to the state. It seems both efficient and sensible to allow the types of people identified above to pursue art and education through art, under the final censorship and review of the current generation of rulers.

Interestingly, the idea that the only legitimate artists will be people who are also philosophers has parallels with aspects of the Hegelian picture of modern art drawn by Danto. Legitimate art in the Republic might be called-and indeed is called by Tate- "true, or philosophical, imitation." Such "imitation" would be direct imitation of the forms themselves and, therefore, would be capable of producing a direct copy of reality (the form) rather than one mediated by an image of the form (an object). ${ }^{13}$ This art of true or direct imitation would only be possible for philosophers, for only philosophers are capable of apprehending the forms. Given that this art is a direct copy of the form, we are presented with the question of what this art would look like. Such art, practiced by philosophers, could not consist merely of images in the sense in which we normally think of them. We can ask again, what would be the image of the form of courage (other than the courageous act)? We are led to the conclusion that acceptable Platonic "art"in particular, that art concerned with things that cannot be per- 
ceived with the senses-would look a great deal like philosophy! Insofar as the art of the Republic comes to resemble philosophy, it comes to resemble Danto's characterization of modern art as theoryladen to the point of becoming philosophical.

Arthur Danto's controversial article "The End of Art" presents three stages in the history of art, and three theories and styles that correspond to the stages. Art progresses from the mimetic stage to the expressive stage and finally to what might be termed "posthistoric art." We are concerned with the art and artist of the latter two stages, and with the similarities that they may bear to the Platonic philosopher-artist we have described. It is with the second and third stages that Danto tells us art becomes less and less mimetic and more and more theoretical. "Objects became less and less recognizable and finally disappeared altogether in Abstract Expressionism." $1+$ Nothing, it would seem, would please Plato more that to see art become less concerned with overt physical mimesis and more concerned with theory (philosophy). It is because art is indifferent to the forms that imitation in art remains three steps removed from truth. Art that creates while observing the forms would be art that is truly creative. Danto describes this expressive type of art as giving the viewer insight into the mind of the artist. This, too, would appeal to Plato if the artists were indeed philosophers.

Would insight into the mind of a philosopher who has successfully apprehended the forms be fruitful for a commoner, a nonguardian - who has not apprehended the forms, and may actually be unable to do so? On one hand, it could be that such insight would be beneficial to the commoner due to the subtle influence of the example provided by the philosopher. Indeed, given Plato's model, a good example would influence the viewer for the better, just as an example of bad imitation would result in a negative influence. However, there is also the possibility of the commoner misinterpreting the example provided by the philosopher-artist. The commoner, recall, was unable to "make the grade" during the initial childhood testing process for guardians. If one is unable to perceive the forms themselves, what would enable him to correctly interpret copies of these forms-even Tate's "direct copies of reality"-with any greater success? It seems now that we must fur- 
ther restrict the domain of art in the Republic. Not only will philosophers be the only artists; they will be the only ones allowed to view art.

However, perhaps this problem can also be overcome. Plato is concerned with art primarily for its power as an educational tool, power that can have either good or bad results. Conceived thus, art could be the very instrument-indeed, the only instrument-through which commoners would be able to get a fleeting and partial glimpse of the forms. And some acquaintance with the forms (as long as it is the result of true knowledge of the form) is better than none. A good poetic work of art by a person who understands the form of courage will provide a concrete example for someone who is not able to apprehend the form of courage on their own, just as the courageous act will provide a concrete example of the form of courage.

\section{Conclusion}

Plato and Danto both maintain, in their respective ways, that mimesis is inadequate to account for art. For Danto, mimetic art is made insignificant by the advent of mimetic technology, leading in turn to expressive and philosophic art. For Plato, bad mimetic art has always been deceptive and untrue insofar as it is at best a third generation copy of the form. While art must approach philosophy to be worthwhile for Plato, art is destined to do so from Danto's perspective. Ultimately, Danto tells us, in art "objects approach zero as their theory approaches infinity, so that virtually all there is at the end is theory, art having finally become vaporized in a dazzle of pure thought ..."15 This seems, after a fashion, to be a good approximation of what would occur in the theorized good imitation of Plato's Republic. ${ }^{16}$ The essence of good imitation is that it imitates the form itself, presenting an image of the form for those who are unable to grasp the form itself due to youth (potential guardian children) or constitution (all citizens who are not "golden"). This image would not necessarily resemble the form, but would somehow manifest the form. In other words, the painting that imitates the form of humanity might, in fact, appear 
quite abstract and look nothing like an actual physical personthough both the physical person and the "good" mimetic painting are reflections once removed from the form.

Given these observations and speculations, the time has come to answer the question that this essay has repeatedly deferred: What would the good imitative art of the polis look like? The difficulty of providing concrete examples of good art has plagued several prominent aesthetic thinkers, for example, Kant. Given the restrictions placed on art-with which we are now very familiarthe poetry of the Republic would have to be something like a somewhat tedious and heavy-handed moral story. Poetry would consist of primarily narration, interspersed with imitation of good men and women. The narration would consist of the explanation of all events and the actions of imperfect people. In addition, the narration would include-if the poetry were to be as effective as possible-philosophical explanations and arguments tailored to the level of sophistication of the audience. The effect of imitating of good people would only be heightened because this imitation would be the only part of the poem that would be enjoyable in the traditional sense-because of the elements that we commonly associate with theater. This form of poetry would be highly effective for Plato's purposes. The poetry would educate overtly in the form of philosophical explanations in the narration of the story and educate covertly via the seductive power of (good) imitation. While this type of poetry might be effective for Plato's purposes, it is very far indeed from what is commonly understood to be art. Although modern art has done nothing if not challenge the "common conception" of art, the heavy-handed artistic indoctrination that Plato reserves for.the polis is not something that would be likely to draw large crowds. It may be possible to save art in Plato's $R e$ public; however, this victory remains a pyrrhic one given the "art" that remains. ${ }^{17}$

The discussion of imitation within the Republic has led us to examine the relationship between art and philosophy, and to an interesting - if somewhat unusual-comparison of Plato's good imitation and the theory-laden art of Danto's second and third models. This comparison is based on the relation of art to philosophy: the more art comes to resemble philosophy, the more truly it imi- 
tates (for Plato) or the further along it is in its inevitable evolution (for Danto). Thus Platonic good imitation would be a form of philosophy, insofar as the good imitator is creating copies of the form as directly as if he were acting in his other capacities as a guardian. The philosopher is the good imitator, and good imitation is philosophy-not for the betterment of the self, but for the betterment of others.

\section{Notes}

'Although the Soviet Union and Nazi Germany did not outlaw art, they did censor art and attempt to bend it to the purposes of the state. Describing and analyzing the uses to which art was put in both these regimes would necessitate a book. However, it can be argued that the perversions some art underwent in such societies may in a sense be worse than the mere exclusion or outlawing of art (although 'underground' art continued to flourish in even these barren settings). Plato himself may be guilty of these same crimes against art in the Republic, a topic to which we will return in the conclusion of this paper.

${ }^{2}$ The analysis in this essay is based on the translated works of Plato and, therefore, does not presume insight into philological subtleties of the text. Multiple translations of the Republic were consulted; however, for the sake of consistency, quotations are taken from the version found in The Collected Dialogues of Plato, Edith Hamilton and Huntington Cairns eds. (Princeton, NJ: Princeton University Press, 1989), 575-844.

${ }^{3}$ There are many lies that Plato sanctions in developing his plan for the Republic. For example, he takes as a matter of fact that there will be false stories told to the children when they are young ( $377 \mathrm{ff} ., 415$, etc.). Note, however, that the blind obedience to the strict morality developed by these false stories leads to a potential breakdown in some guardians when they are exposed in the course of their training to the art of dialectic (538e). In addition to educational lies, there is the more disturbing development of lies to cover up the state mandated policy of eugenics and keep the infanticide hidden from all except the guardians who carry out this function $(460 \mathrm{c})$. Plato's inadequate excuse for these lies at $382 \mathrm{~cd}$ does not alleviate the contradiction inherent in the search for truth (and justice) through a city steeped in governmental lies. Such passages as these-along with Plato's failure at Syracuse-tend to imply that the Republic may serve better as a guide for the ordering our souls that it does as a blueprint for political successes. 
${ }^{4}$ For examples of imitation proper to the good man, see 396de.

'Both J. Tate ("'Imitation' in Plato's Republic," in Classical Quarterly, vol. 22 [1928], 16-23.) and E. Belfiore ("A Theory of Imitation in Plato's Republic," in Transactions of the American Philological Association, 114 [1984], 121-146.) recognize that Plato's initial statement in Book $\mathrm{X}$ is referring, not to all types of imitation or imitation in general, but to the specific kind of imitation which had already been determined to be bad in Book III. The understanding of the distinction between "good imitation" and "bad imitation" in this paper is taken, in part, from a reading of Tate and Belfiore.

${ }^{6}$ See Republic 505-518 passim.

${ }^{7} \mathrm{~J}$. Tate, "Imitation in Plato's Republic," 19.

${ }^{8}$ Ibid. Tate can make this inference because of Plato's description of the painter who uses the "divine paradigm" rather than the mirror image $(500-501 \mathrm{c})$. There is a difference between common statecraft and "genuine statecraft." Genuine statecraft rules the state with the forms in mind. In a similar manner there exists both mere imitative painting, and "genuine painting" which represents (i.e. imitates) with the forms in mind.

'It is, however, possible to attack this foundation itself. Although Plato attempts to hold fast to the rule of one person, one expertise, this distinction begins to break down in Book X when discussing knowledge and the philosopher (see the discussion at $601 \mathrm{c}$ ff.). It is unclear if Plato really believes that the philosopher who has apprehended the forms knows the art of making horse tack better than the smith and the leatherworker. However, odds are that most equestrians would choose to trust the tack made by the man who does not know (the craftsman) that that made by the man who does know (the philosopher).

10 Arthur Danto, "The End of Art," in The Death of Art, ed. Berel Lang (Haven Publications, Inc), 5-35.

"Arthur C. Danto, "The End of Art," 34.

12 These proposals are founded on the assumption that the older guardians will become too infirm for the duties of governing while they are still capable of verbally communicating the truth through poetry. This assumption itself is questionable in Plato's Republic. The guardians do not even begin their final phase of training for governing until they are fifty years old! Plato obviously wants the city to be run by the most experienced (thus, the oldest) capable guardians. However, against this difficulty lies the fact that Plato also believes that each successive generation of guardians will be more capable than the previous generation due to the practice of selective breeding and infanticide. Thus, the guardians coming up through the ranks would be better versions of the men and women who they will be replacing, once their education is complete. 
It is easy to conceive of a time when these younger guardians are experienced and capable enough to be ready to take over the reigns of the $R e$ public while the older generation has not yet died off.

${ }^{13}$ As long as we are making this unusual comparison between Plato and Danto, it is worth noting that the distinction between "good imitation" and "bad imitation" is one of two entirely different kinds of artistic endeavors. Good imitation is art that could only be accounted to under what Danto calls the "Reality Theory" (RT) of art, while bad imitation would still be accounted for with the "Imitative Theory" (IT). These two kinds of art are distinguished by their goals. Art that can be understood with the IT is attempting to imitate the visually perceived world. However, some art cannot be accounted for with the IT and must be understood in terms of the RT of art. Such art is not imitative, but creative. RT art creates in a way that is "if no more real than what carpenters wrought [it is] at least no less real" (Arthur Danto, "The Artworld," in Art and Its Significance, ed. Stephen David Ross (Albany, NY: State University of New York Press, 1994), 470-482). The distinction between art that can be accounted for with IT and art that can be accounted for with RT is exactly the distinction between good and bad imitation that we are trying to make. Bad imitation is merely imitating. Good imitation is actually creating (although this is still an imitation at one remove from the form within Plato's metaphysical framework).

${ }^{14}$ Arthur Danto, "The End of Art," 24.

15 Ibid., 31.

${ }^{16}$ The Republic itself can be seen in these terms. The ideal art of Plato's state would contain lots of philosophy and narration along with a bit of entertainment in the form of good imitation. Although the Republic itself would no doubt fail its own test if "performed" with the imitation of people like Thrasymachus, if performed well, it would no doubt be something akin to the type of poetic entertainment Plato envisions. The proper performance of the Republic would be something like a monotone narrative with the exception of imitating Socrates.

${ }^{17}$ This is not to imply that modern artistic expression is without merit. Rather we are attempting to indicate that the art left in the Republic would be difficult for the commoners to understand and would thus not be initially or instinctively compelling to them. Witness the modern aversion to modern art among people who are unfamiliar with the theories behind the artworks. In a similar manner, the people of the Republic would have to be educated into an understanding of the art allowed in the polis. 